\title{
Current Evidence on Abuse and Misuse of Gabapentinoids
}

\author{
Staffan Hägg' ${ }^{1}$ · Anna K. Jönsson ${ }^{2,3} \cdot$ Johan Ahlner ${ }^{2,3}$
}

Published online: 28 August 2020

(c) The Author(s) 2020

\begin{abstract}
This review summarizes current evidence on the abuse and misuse of the gabapentinoids pregabalin and gabapentin. Pharmacovigilance studies, register-based studies, surveys, clinical toxicology studies, and forensic toxicology studies were identified and scrutinized with the goal to define the problem, identify risk factors, and discuss possible methods to reduce the potential for abuse and misuse. Studies found that gabapentinoids are abused and misused and that individuals with a history of psychiatric disorders or substance use disorder seem to be at high risk. Moreover, some evidence supports the notion that patients with opioid use disorders may be at an increased risk of abusing gabapentinoids. Available evidence also suggests that abuse and misuse are more frequent in users of pregabalin compared with users of gabapentin. Health professionals and prescribers should be aware of the risk for misuse of pregabalin and gabapentin, which eventually could lead to abuse, substance dependence, and intoxications. Prescribing to patients belonging to risk populations such as those with psychiatric disorders or substance use disorder should be avoided if possible and, if prescribed, signs of misuse and abuse should be monitored.
\end{abstract}

\section{Key Points}

The gabapentinoids pregabalin and gabapentin have a potential for being abused and misused, which could result in substance dependence and intoxications.

Individuals with a history of psychiatric disorders or substance use disorder seem to be at high risk for misuse and abuse.

Some evidence suggests that patients with opioid use disorders may be at an increased risk of abusing gabapentinoids.

Available evidence suggests that abuse and misuse are more frequent in users of pregabalin compared with gabapentin.

Staffan Hägg

staffan.hagg@liu.se

1 Futurum, Jönköping, Region Jönköping County and Department of Biomedicine and Clinical Sciences, Faculty of Medicine and Health Sciences, Linköping University, Futurum, Hus B4, Ryhov Hospital, S-551 85 Jönköping, Sweden

2 Division of Drug Research, Department of Biomedicine and Clinical Sciences, Faculty of Medicine and Health Sciences, Linköping University, Linköping, Sweden

3 Department of Forensic Genetics and Forensic Chemistry, National Board of Forensic Medicine, Linköping, Sweden

\section{Introduction}

The gabapentinoids, pregabalin and gabapentin, are widely used for the treatment of epileptic and pain disorders. Pregabalin is also used for generalized anxiety disorder, diabetic peripheral neuropathy, post-herpetic neuralgia, and fibromyalgia [1]. Another gabapentinoid, mirogabalin, is in clinical development and has recently been introduced in Japan for the treatment of peripheral neuropathic pain [2].

Gabapentinoids are structurally similar to gamma-aminobutyric acid (GABA); however, they do not act on GABA receptors or have effects on GABA synthesis or metabolism. They are selective ligands for the alpha-2-delta subunit of voltage-gated calcium channels (VGCC) and have been demonstrated to restrain stimulus-dependent synaptic transmitter release, mainly the excitatory transmitters glutamate and norepinephrine [3, 4]. Gabapentinoids lead to a moderate dose-dependent increase of the extracellular GABA level in the brain $[3,5]$, causing weak GABAmimetic features such as relaxation and euphoria. These effects are experienced especially in the beginning of drug therapy and after use of supratherapeutic doses.

The possible risk of abuse/addiction for pregabalin was studied in vitro and in vivo during development of the substance. In a conditioned place preference test study in rats, it was found that pregabalin did not have rewarding properties and even decreased those of morphine [6]. A 
later study also in rats [7] challenged these results and found that pregabalin produced the same rewarding effects under painful conditions as under pain-free conditions when given in supratherapeutic doses. In a recent study on mice [8], pregabalin produced a rewarding effect in a conditioned place preference test. In another animal study [9], mice were exposed to a partial sciatic nerve ligation or were in a control group. Both groups developed selfadministration behavior indicating potential abuse liability of pregabalin. In a small study in monkeys $(n=4)$ mentioned in a review [10], self-administration of greater than ten injections a day during initial access to the drug was observed, indicating that pregabalin produced reinforcing effects.

In a review of 102 pregabalin clinical trials [11], euphoria was reported in 14 studies as an adverse effect with a prevalence between 1 and 10\% (26\% in one study). Patients with various diagnoses such as fibromyalgia, painful neuropathies, post-herpetic neuralgia, and generalized anxiety disorder, but also healthy volunteers were included in these studies. During the last few years, several reviews of the abuse and misuse of gabapentin and pregabalin have been published, each year adding several original publications. Our aims were to update and summarize the available evidence, describe the extent of the problem, identify risk factors, and discuss possible methods to reduce the risk for abuse and misuse.

\section{Methods}

\subsection{Search Strategy}

For this narrative literature review, PubMed was systematically searched for articles published through 31 December, 2019 utilizing the following search strategy: pregabalin OR gabapentin OR gabapentinoid AND one of the following qualifiers: abuse, misuse, overdose, or substance related disorders. In a separate search: pregabalin OR gabapentin AND forensic AND toxicology were used. Additional studies were obtained through a citation review of identified articles. JA performed the literature search.

\subsection{Study Selection}

Articles were screened for relevance through a title and abstract review. Full texts were retrieved for articles deemed relevant based on the initial assessment. Articles were considered relevant if related to gabapentinoid abuse, misuse, dependence, addiction, and overdoses in humans. Only articles written in English were considered for inclusion. Inclusion in the study was based on author consensus after a full-text review. Included studies were categorised as pharmacovigilance studies (data on reported adverse drug events), register studies (data on prescriptions, patients records), surveys (self-reported data on abuse and misuse), clinical toxicology (data on clinical intoxications), and forensic toxicology (data on post-mortem cases and from individuals driving under the influence of drugs [DUID]). Case reports and reviews were excluded as well as animal and in vitro studies. Duplicates were identified through a manual check. In total, 432 different articles were initially identified and read, 391 articles were removed and not included in the analysis. Hence, the remaining 41 articles were included and are presented in the tables.

\subsection{Data Extraction and Assessments}

To compile and describe data, details of included studies were extracted and imported to tables. JA, AKJ, and SH extracted the information from the articles. Each of the authors conducted a qualitative assessment of the identified studies and an author consensus resulted in the final tables in the publication. The information extracted from the articles were, with their definitions in parentheses: drug (the substance/s studied), time period (study period), country (the country where the data was retrieved from), study design, data source (where the data was retrieved), study population (number of individuals included in the study), and results (the outcome of the study). No study authors were contacted for additional information or clarifications of the studies included in this review.

\subsection{Definitions of Misuse and Abuse}

'Misuse' sometimes refers to all uses of illegal drugs [12]. For medicinal drugs, it may mean any types of inappropriate use, irrespective of whether there is any dependency involved, and misuse might be accidental or even unrecognized by the patient [13]. The concept of misuse in this review refers to all types of such inappropriate use. 'Abuse' on the other hand, is an active and recognized non-medical use of a substance, in most cases linked to dependence/ addiction and (often) involving higher doses than normal [14]. Addiction or drug addiction is a neuropsychiatric disorder characterized by a recurring desire to continue taking the drug despite harmful consequences [15]. Although individual studies included in this review may have used slightly different definitions when discussing the results, we used the above-stated definitions. 


\section{Results}

\subsection{Clinical and Epidemiological Studies}

There are several pharmacovigilance studies describing the abuse and misuse of gabapentinoids (Table 1). Two recent US studies reported data from the US Food and Drug Administration adverse event reporting system [16, 17], included pregabalin and gabapentin reports during the period 2012-16 [17] and 2005-12 [16]. Both studies, partly covering the same data, found a higher proportion of abuserelated reports for pregabalin (10.2\% of 571 reports [17] and $26.1 \%$ of 97,813 reports [16]) compared with gabapentin (5.7\% of 10,038 reports [17] and $22.9 \%$ of 99,977 reports [16]). A study [18] based on the data from the Eudravigilance database (spontaneously reported adverse drug reactions in the European Union) found a somewhat higher proportion of abuse-related reports for pregabalin $(6.6 \%$, of 115,616 reports) compared with gabapentin ( $4.8 \%$ of 90,166 reports), but the proportion of reports with a fatal outcome was more frequent in gabapentin reports compared with pregabalin reports $(0.095 \%$ vs $0.023 \%)$. Concomitant use with opioids was often noted in these cases. A second study [43] (not included in Table 1) also using Eudravigilance data reported 13 cases of nasal pregabalin use in individuals with current or past substance dependency or misuse. A fatal outcome was observed in two of these cases. Three other European studies [19-21], using data from the national reporting systems, found abuse-related reports on pregabalin. The proportion of abuse-related reports was $1.5 \%$ of 521 reports in France [19], 3.5\% of 15,551 reports in Germany [20], and $8.1 \%$ of 198 reports in Sweden [21].

\subsection{Data from Drug Utilization/Prescription Databases}

In recent years, a number of cohort studies concerning abuse of pregabalin and gabapentin have been published indicating that prescription of gabapentinoids as well as abuse/misuse have increased. An Australian study [22] showed that misuse-related ambulance attendances concerning pregabalin increased from 0.3 to 3.3 cases per 100,000 inhabitants from the first half of 2012 to the second half of 2017. The attendance rate was significantly correlated with prescription rates in Australia. Sedatives were often misused in combination with pregabalin $(68 \%, 812$ attendances), particularly benzodiazepines (37\%, 440 attendances). A US cohort study [23] investigating 2368 drug arrests in 2016 found that $22.7 \%$ concerned gabapentin and $1.7 \%$ pregabalin. Misuse rates of gabapentin steadily increased from zero cases in 2002 to 0.03 cases per 100,000 inhabitants in 2015 according to a US survey of drug diversion [24]. In that study, gabapentin was often misused in combination with prescription opioids or with illegal opiates such as heroin.

A recent French population-based cohort study [26] found that misuse is more likely to occur in new and younger users of pregabalin. A primary addiction was developed after the first episode of drug misuse in $10.7 \%$ of pregabalin users and $11.6 \%$ of gabapentin misusers. Some studies recorded the doses taken by patients prescribed gabapentinoids. In a UK study [31], a dose above the maximum approved dose (> $600 \mathrm{mg}$ /day) was observed in $1.0 \%$ of 13,480 pregabalin-treated patients. A history of substances abuse was observed in $18.4 \%$ of 136 patients compared with $14.0 \%$ of 13,480 patients in the full population. In contrast, a Swedish study reported that $8.5 \%$ of 48,550 pregabalin users were prescribed doses higher than the maximum approved dose (> $600 \mathrm{mg} /$ day) [33]. Prevalence of addiction history (i.e., previous drug treatment or diagnosis for addictive disorder) in the Swedish cohort showed a wider gap between those receiving doses within the recommended maximum (20\%) and those exceeding it (31\%). Risk factors for being prescribed $>600 \mathrm{mg} /$ day of pregabalin included sex (male), age (ages of 18-29 years vs $\geq 65$ years), low income, epilepsy, previous substance use disorder treatment/diagnosis, and having previously received high doses of drugs with abuse potential. Similar figures were found in a Danish drug utilization study [32], with $9.6 \%$ and $6.5 \%$ of the 42,520 user cohort receiving $>600 \mathrm{mg} /$ day for 6 and $>12$ months, respectively. Male individuals and individuals prescribed antipsychotics and benzodiazepines were significantly more likely to receive doses above this recommended maximum.

A US study of insurance claim data from 2013 to 2015 [28] found that the top $1 \%$ of gabapentin users filled prescriptions for mean (median) doses of 11,274 (9534) mg/day, representing more than three times the maximum recommended dose. Intoxications, suicide, and accidents among those using gabapentinoids have also been described using drug utilization data. In Sweden, 5.2\% of 191,971 individuals with at least two consecutive prescriptions for gabapentinoids were treated for suicidal behavior or died from suicide [25]. Pregabalin users had a higher risk for these outcomes compared with gabapentin users.

An Australian cohort study [27] found reports of intentional pregabalin poisonings increasing by $58 \%$ per year during the study period 2005-16. Pregabalin overdose was frequently accompanied by co-intake of opioids, benzodiazepines, and illicit drugs. Moreover, these patients had high rates of psychiatric and substance use comorbidities; $15 \%$ of pregabalin users were considered to be at high risk of misuse, and they were more likely to be younger, male, have co-prescriptions of benzodiazepines or opioids, have more individual prescribers, and higher pregabalin dosage dispensed. A UK study [29] found that pregabalin and gabapentin prescriptions increased approximately $24 \%$ per year from 


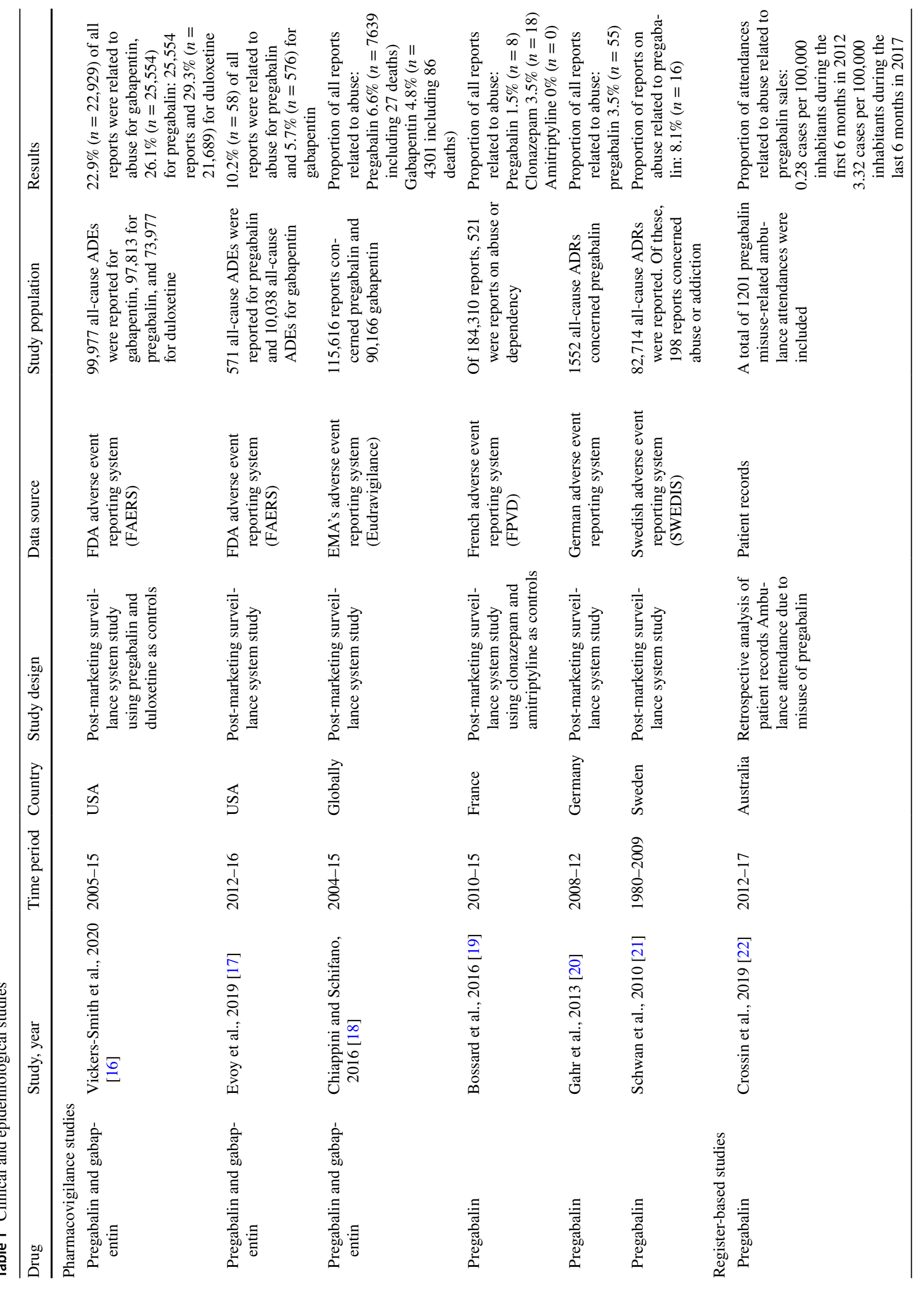




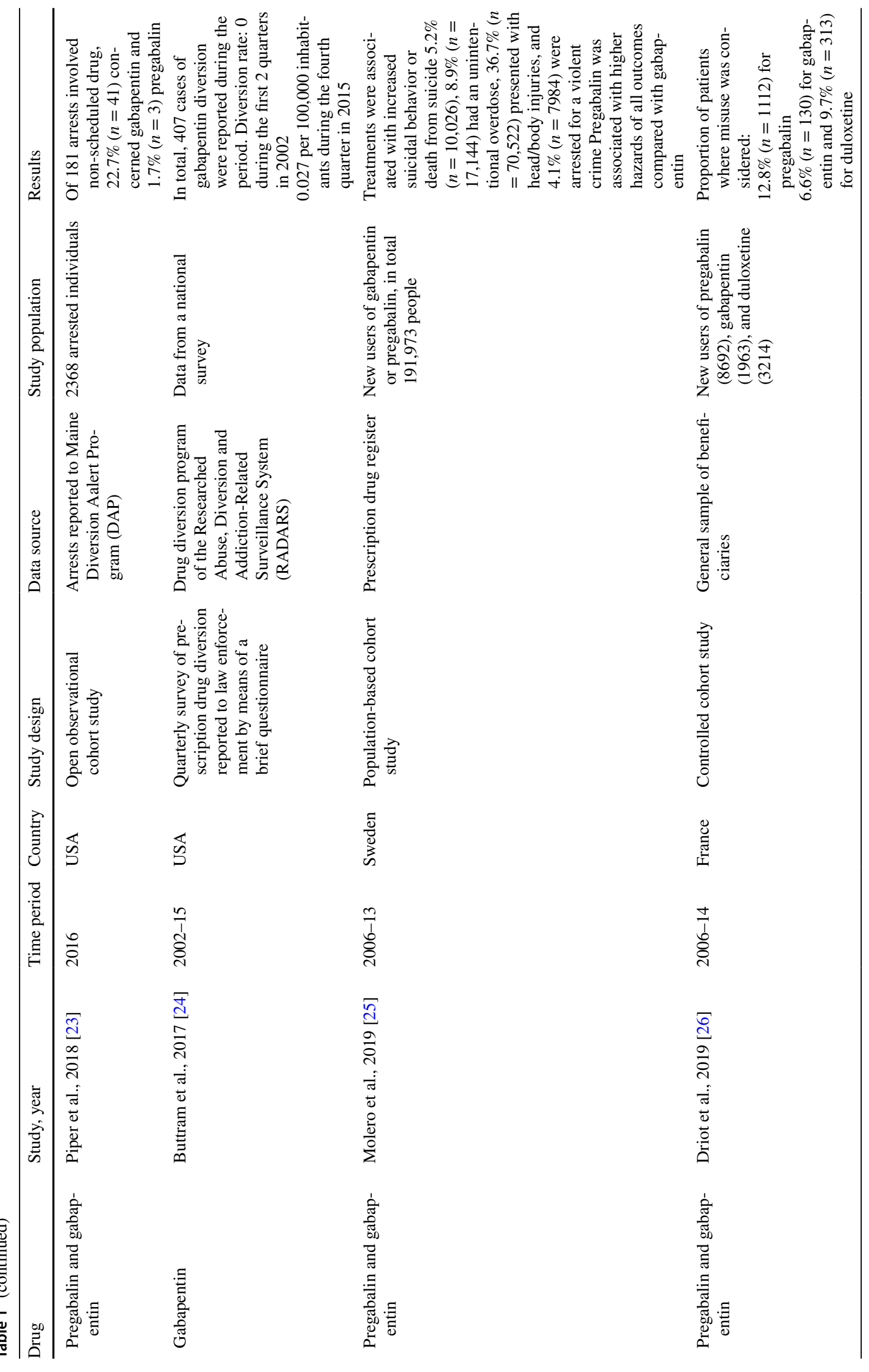




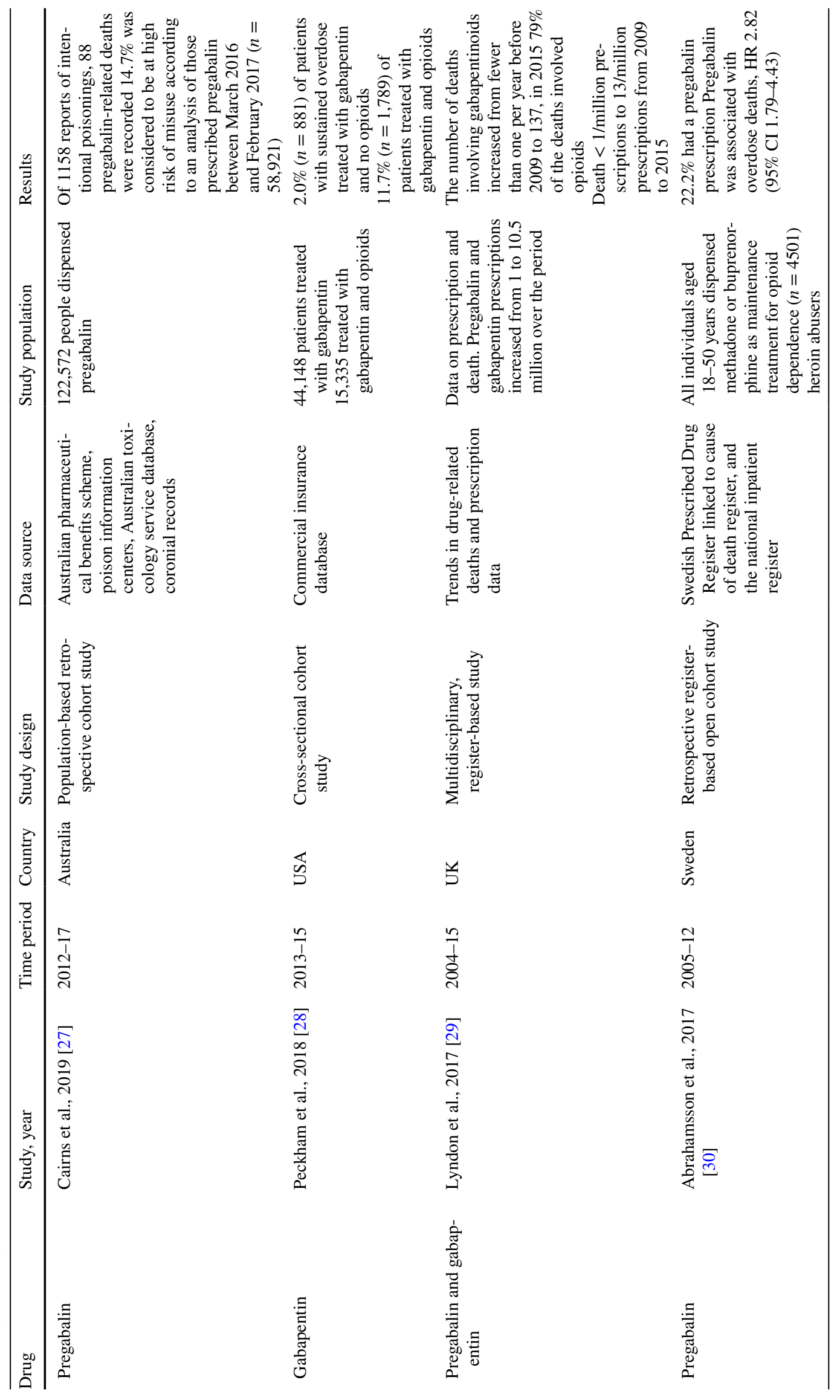




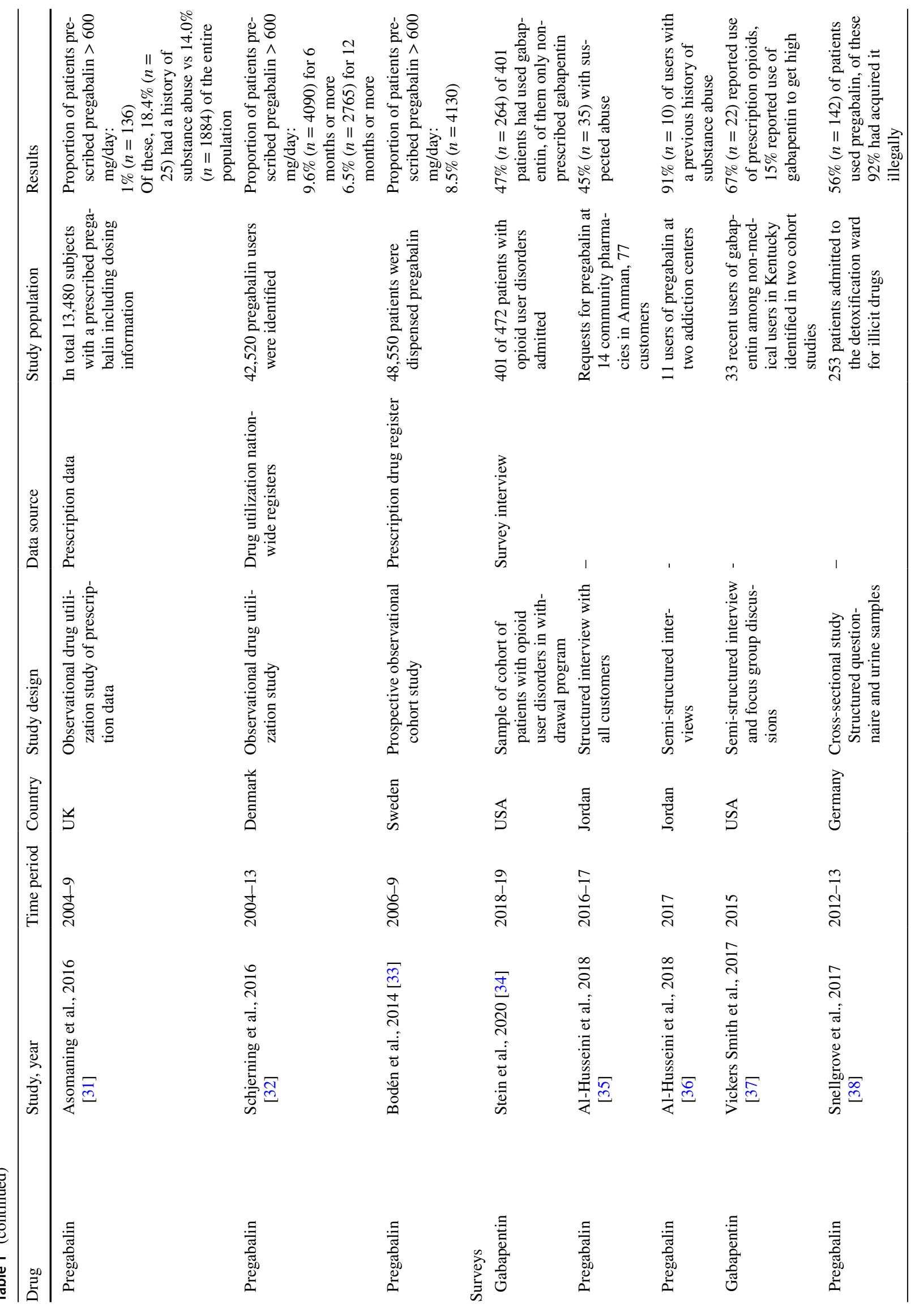




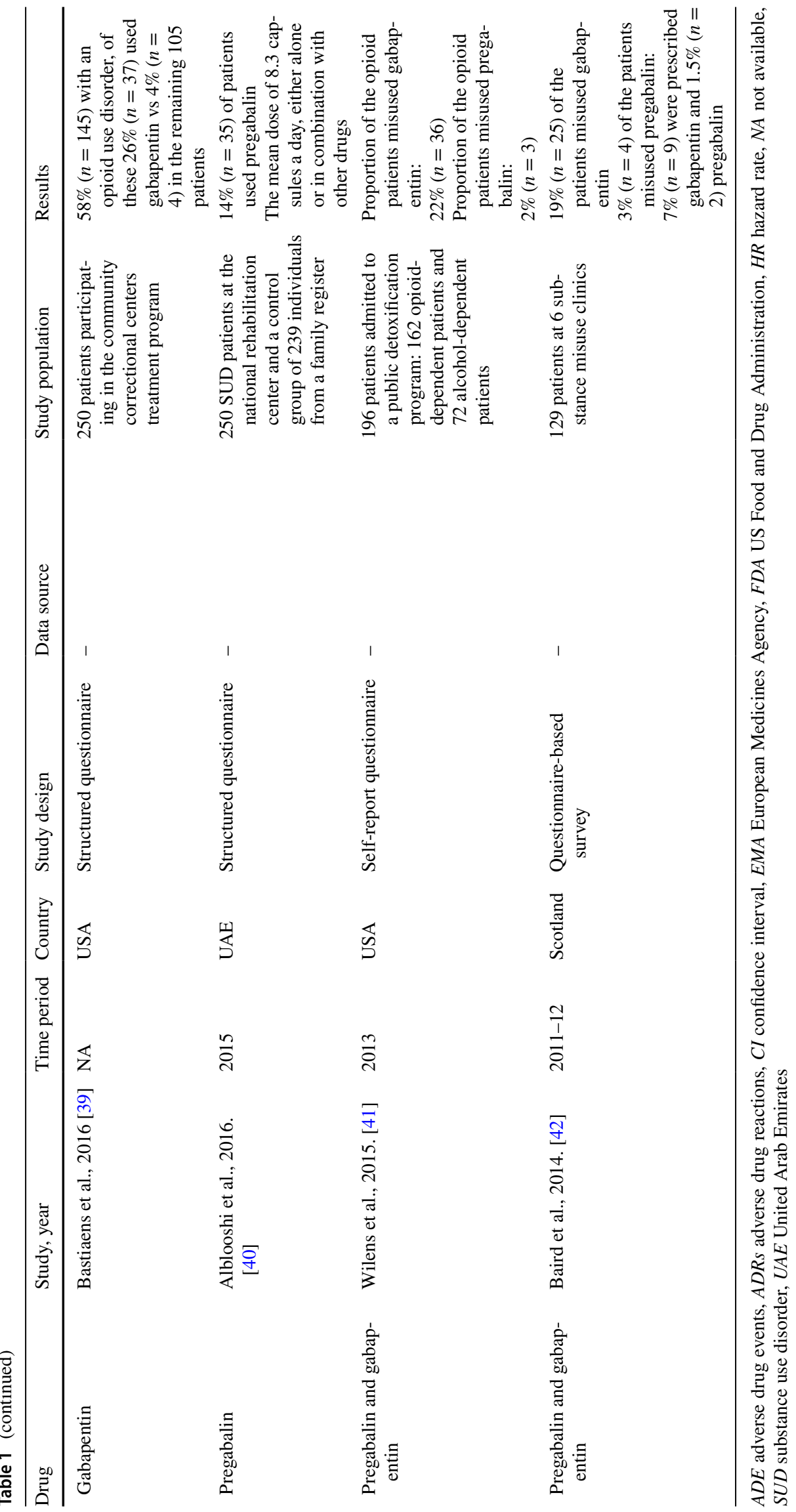




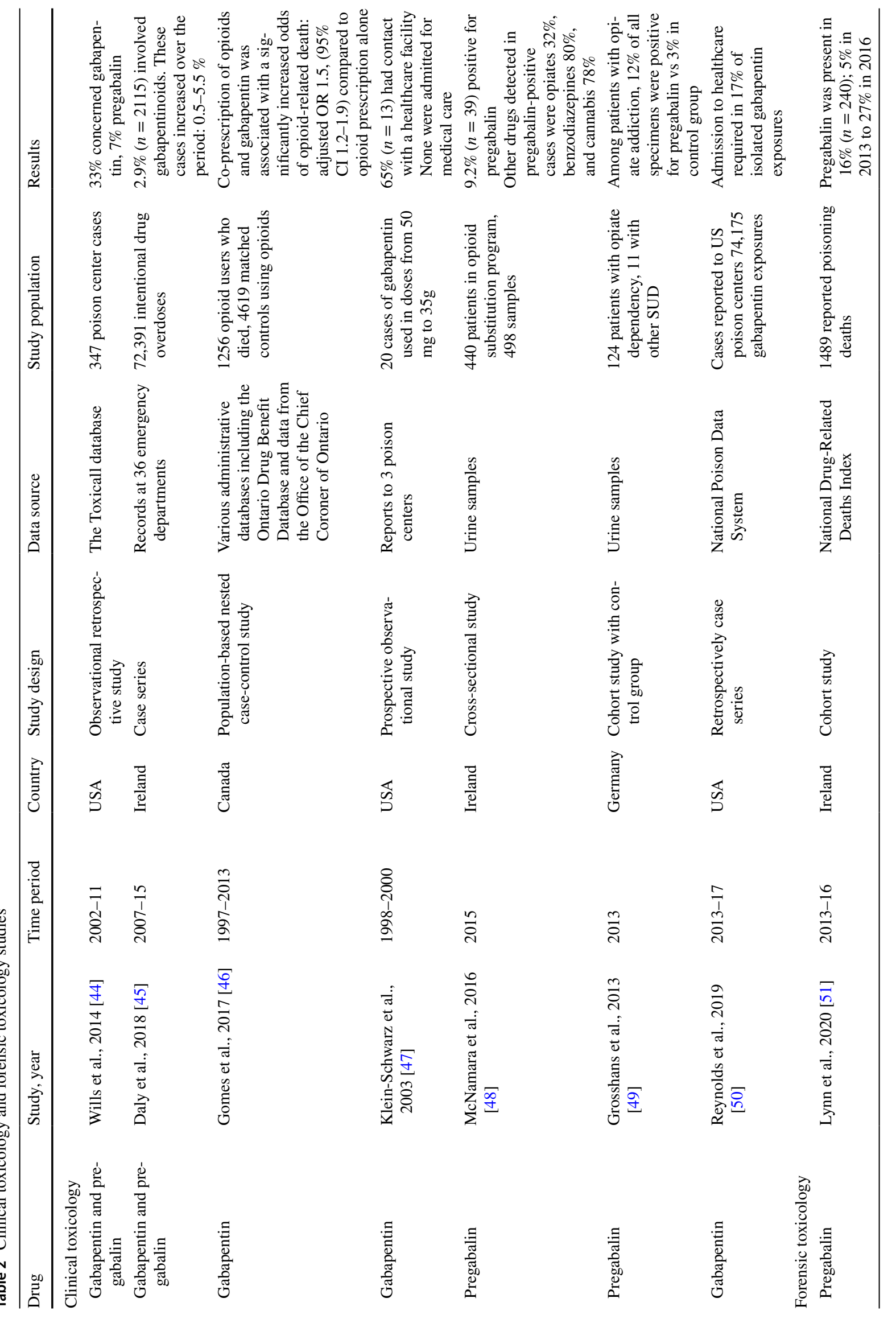




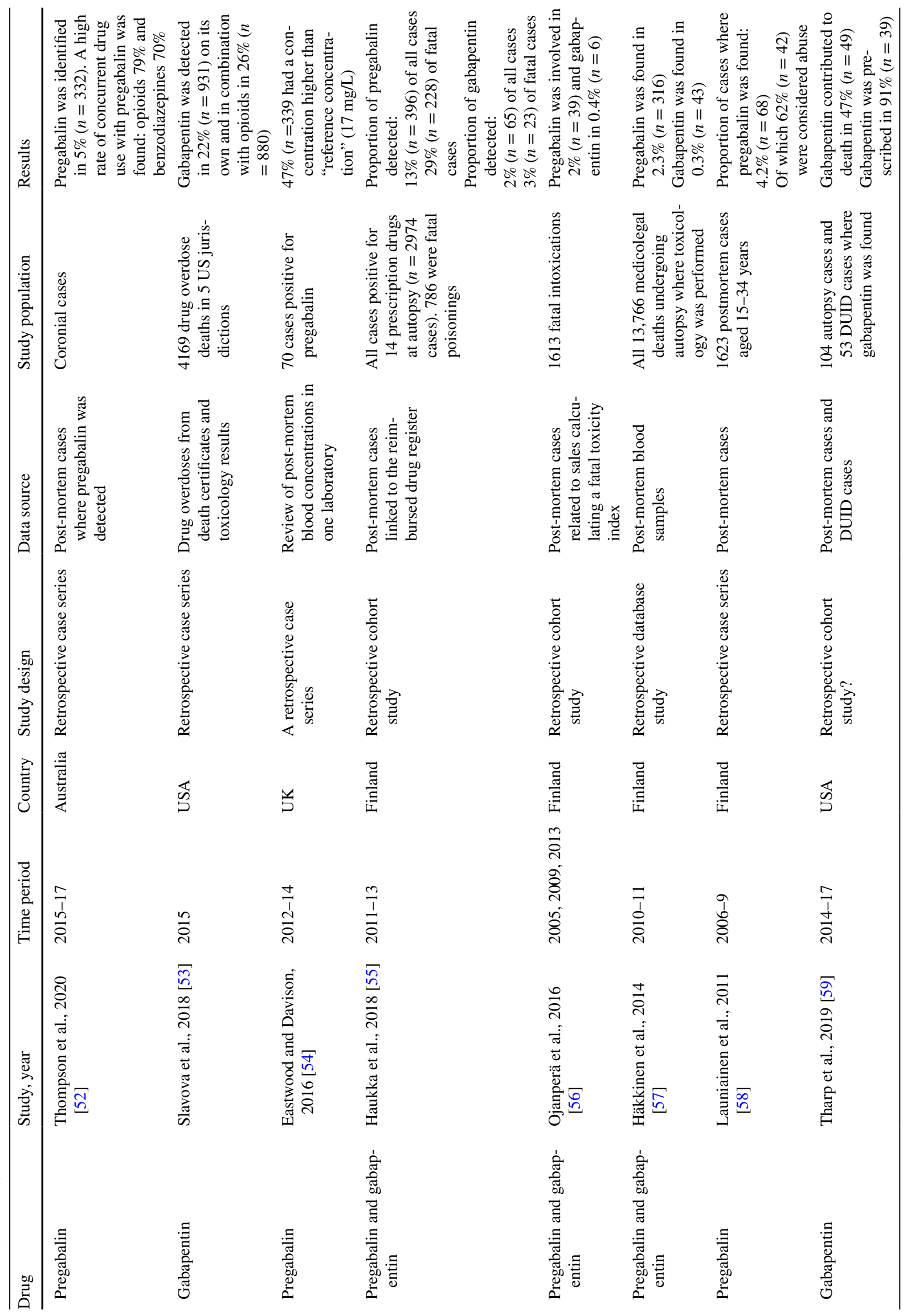




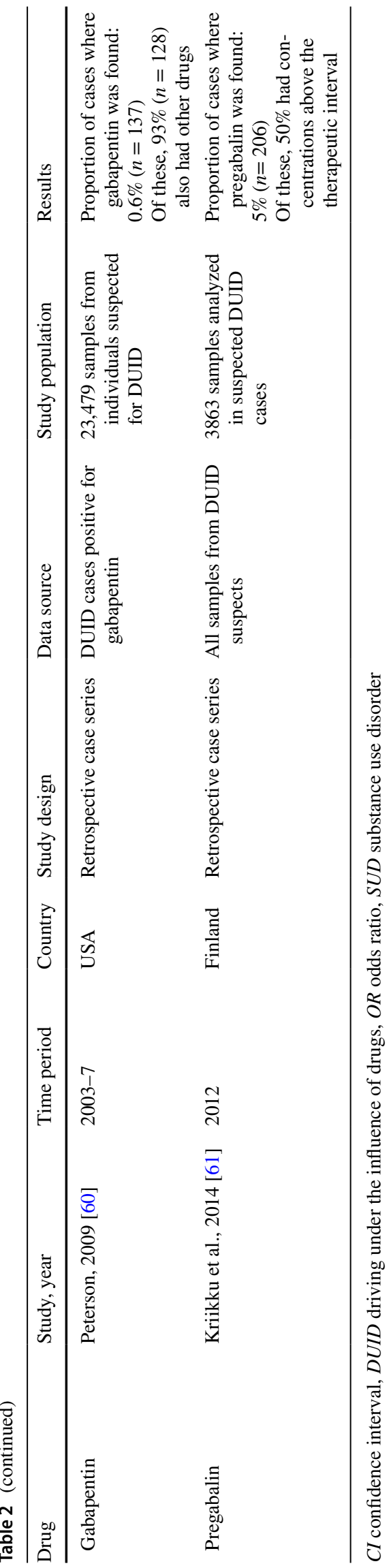

1 million in 2004 to 10.5 million in 2015. Gabapentin deaths also increased during the same period from $<1$ in 2009 to 137 in 2015 . Opioids were involved in $79 \%$ of these deaths.

\subsection{Indications of Abuse/Non-Medical Use in Surveys/Questionnaires}

During recent years, a numbers of surveys have been conducted among users of gabapentinoids in countries such as USA [37, 39, 41], Germany [38], Scotland [42], Jordan [35, 36], and United Arab Emirates [40]. In a US study [37], 33 individuals self-reported recent non-medical gabapentin use. Their regular gabapentin use began often $>10$ years prior, typically prescribed for a legitimate medical reason (e.g., pain, anxiety, opioid detoxification), albeit often off-label. Participants took gabapentin with other drugs including buprenorphine, opioids, cocaine, and caffeine to produce desired effects such as muscle relaxation, pain reduction, sleep, sensation of drunkenness, and euphoria.

At the Center for Psychiatry in Southern Germany [38], 253 out of 281 patients on a detoxification ward for illicit drugs self-reported using pregabalin at least once and $92 \%$ admitted to obtaining at least some of it from illegal sources. Reasons for pregabalin use included opioid withdrawal symptoms, augmentation of other substances' psychotropic effects, and to experience the effects of pregabalin itself. Predictors for pregabalin use were opioid and sedative use as well as younger age.

In the second US study [39], 250 former inmates with substance use disorders living in a correctional community center responded to a questionnaire. Prescription drug misuse was reported in $62 \%$ of the patients and $16 \%$ reported misuse of gabapentin in the past. A significantly higher proportion of patients with an opioid use disorder (26\%) endorsed gabapentin abuse compared with $4 \%$ of those without an opioid use disorder.

In another study [42], a questionnaire-based survey was carried out in six substance misuse clinics in Scotland. Among the 129 patients recruited, $8 \%$ reported that they were prescribed gabapentinoids and $22 \%$ admitted that they were abusing gabapentinoids and of these, 38\% abused gabapentinoids to potentiate euphoria experienced from methadone.

\subsection{Gabapentinoids and Toxicology: Clinical and Forensic}

\subsubsection{Clinical Toxicology}

Clinical and forensic toxicological studies are summarized in Table 2. A study from Ireland [45] showed that gabapentinoids were involved in $2.9 \%$ of the 72,391 intentional drug overdoses recorded at emergency departments. These 
intentional drug overdoses increased from $0.5 \%$ in 2007 to $5.5 \%$ in 2015 . In a study of opioid-related deaths [46], co-prescription of opioids and gabapentin was significantly associated with opioid-related death relative to opioid prescription alone. Moreover, moderate- and high-dose gabapentin use was associated with an increased risk for opioidrelated death. In a study of 347 cases of overdoses of newer anticonvulsants identified in US poison center records, 33\% concerned gabapentin and 7\% pregabalin [44]. Most of the cases where pregabalin and gabapentin were implicated had minor or moderate clinical effects, which is in agreement with a previous study of patients intoxicated with gabapentin [47].

\subsubsection{Forensic Toxicology}

The prevalence of gabapentinoids in forensic settings has been evaluated in a number of studies (Table 2) with a focus on abuse and toxicity. Most of these studies were based on post-mortem data but some were generated by data from suspected DUID cases.

An Irish study found an increase in pregabalin-positive poisoning deaths from 5\% of all cases in 2013 to $26 \%$ in 2016 [51]. The odds of being pregabalin positive increased with female sex, opioid misuse, recent treatment for problem drug use, and the year of death. In a study of 104 forensic autopsy cases in the USA where gabapentin had been detected post-mortem, gabapentin was considered to be directly involved in the death in nearly half of the cases (47\%) [59]. The drug was prescribed legitimately to $91 \%$ of the individuals whose death was gabapentin related, and $84 \%$ had a known history of prescription drug abuse or misuse. In another study, $4.4 \%$ of coronial cases in Australia between 2015 and 2017 were found positive for pregabalin [52]. In a majority of these cases (58\%), the cause of death was drug related and in $40 \%$ a mixed drug toxicity was described. Concurrent drug use was common and opioids were identified in $79 \%$ of all positive cases. Benzodiazepines and antidepressant drugs were also frequent findings. During 2015, gabapentin was found in $22 \%$ of all drug overdose deaths, and $26 \%$ of those positive for opioids, in five US jurisdictions 53].

In a series of 93 fatalities from the UK, where pregabalin was found and considered the cause of death or contributory to death, other drugs were present in all cases; antidepressant drugs were found in more than $90 \%$ of the cases and opioids in $65 \%$ of the cases [62]. In 30 US post-mortem cases where gabapentin was found at autopsy [63], mixed-drug toxicity was determined in $47 \%$ of the cases.

Four Finnish studies have been published on the subject of this article (see Table 2). Haukka et al. [55] published a study where pregabalin was found in 396 and gabapentin in 65 of all forensically investigated deaths during 2011-13.
For pregabalin, 228 cases were fatal poisonings and for gabapentin, 23 were fatal poisonings. For pregabalin, 139 of all cases and for gabapentin 12 of all cases were considered as non-medical use (no prescription within 365 days). Among the cases who died from fatal poisonings, $45 \%$ had non-medical use for pregabalin and $30 \%$ for gabapentin. In another Finnish study [57], pregabalin was found in $2.3 \%$ of all cases subject to forensic toxicology and for gabapentin, the corresponding proportion was $0.3 \%$. Drug abuse was associated with $48 \%$ and $19 \%$ of pregabalin and gabapentin cases, respectively. Pregabalin poisoning accounted for $10 \%$ of all pregabalin cases and gabapentin poisoning for $5 \%$ of all gabapentin cases. In the drug abuser cases, pregabalin poisoning represented $19 \%$, and gabapentin poisoning $12 \%$. Concomitant opioid use was noted in $91 \%$ in the pregabalin abuser group and in $88 \%$ in the gabapentin abuser group.

Three studies focused on DUID cases. The recent US study mentioned above [59] also investigated 53 nonfatal cases of motor vehicle drivers suspected of DUID. In another US study [60], 137 DUID cases were identified whose samples were positive for gabapentin submitted to the Washington State Toxicology Laboratory between 2003 and 2007. The concentrations of gabapentin in blood from DUID cases had a range of $<2.0-24.7 \mathrm{mg} / \mathrm{L}$ with a mean of $8.4 \pm 5.4 \mathrm{mg} / \mathrm{L}$ and a median of $7.0 \mathrm{mg} / \mathrm{L}$. Of the cases studied, only $7 \%$ were positive for gabapentin alone. In Finland [61], pregabalin was detected in 5\% of 3863 cases of DUID suspects in 2012. Serum concentration was above the therapeutic range in nearly $50 \%$ of the cases and other drugs were found in most cases.

\section{Discussion}

Mounting evidence shows that gabapentinoids are abused and misused and that individuals with a history of abuse are at an increased risk. In a previous review, Smith et al. [64] estimated the prevalence of gabapentin abuse and misuse to be $40-65 \%$ among individuals with prescriptions and $15-22 \%$ in populations abusing opioids compared with $1 \%$ in the general population. A lifetime prevalence of misuse of $1.1 \%$ for gabapentin and $0.5 \%$ for pregabalin was also observed in a UK online survey [65] performed by a global market research company. In pharmacovigilance studies based on spontaneous reports of adverse events for pregabalin and gabapentin, $1.5-10 \%$ of reports were classified as misuse, abuse, and/or dependence (Table 1). Abuse and misuse of gabapentinoids seem to have increased in recent years. In the study by Chiappini and Schifano [18], 7639 reports concerning misuse, abuse, or dependence for pregabalin and 4301 for gabapentin were identified using Eudravigilance data for the period 2004-15. More than 75\% of all reports were reported after 2012. 


\subsection{Risk Populations}

Available evidence shows that gabapentinoid abuse is more prevalent among patients with substance use disorders, in particular opioid abuse. There are studies reporting that $15-22 \%$ and $3-68 \%$ of patients with opioid use disorders abuse gabapentin and pregabalin, respectively [39-42, 48, 49, 64]. Although the studies are undertaken in different countries using different methodologies, they support the same general picture. In a study of patients treated for opioid addiction in a substance use disorder clinic in USA [41], 22\% misused gabapentin and 7\% misused pregabalin. That contrasts with those treated for non-opioid addiction where no one misused gabapentinoids. The same pattern was observed in a German study [49]. Patients treated for opioid addiction abused pregabalin in $12 \%$ of the cases, whereas those treated for non-opioid addiction abused pregabalin in only $2 \%$ of the cases. In Italian patients with a history of opiate dependency and in methadone treatment programs where pregabalin was detected in $14 \%$ of hair samples, $57 \%$ of those patients also used other drugs [66]. Among former US inmates, opioid abusers were significantly more likely to misuse gabapentin than those with a non-opioid substance use disorder, $26 \%$ vs $4 \%$ [39]. Other studies confirm high rates of gabapentinoid abuse in opioid addicts [20,21, 42, 64, 66-68]. One study [40] reported that more than $60 \%$ of opioid addicts misused gabapentinoids. A survey among opioid abusers found that on average gabapentin was used recreationally in 25 of the last 30 days [64]. Among 401 participants with opioid use disorder recruited from a managed withdrawal program in the USA, 66\% had used gabapentin [34]. Of these, 20\% had used only prescribed gabapentin, while $32 \%$ had used both prescribed and non-prescribed gabapentin. Moreover, earlier abuse of cocaine has also been mentioned as a risk factor for gabapentinoid abuse [48, 69].

Different reasons why abuse of gabapentinoids is higher among opioid abusers have been proposed. It has been suggested that they might relieve opioid withdrawal syndromes or treat uncontrolled pain $[39,49]$. Another suggested explanation is that with reduced prescribing of opioids and benzodiazepines, patients are substituting other licit or illicit drugs because of the greater availability $[66,70]$. In a small interview study among opioid users, augmenting the opioid high was a common reason for combining a variety of substances with opioids [71]. It has been reported that patients undergoing substance use disorder treatment use gabapentinoid to potentiate the effects of methadone or buprenorphine, as well as to avoid detection during urine monitoring [34, 39, $42,49,72]$. In one study [34], the most common reasons for intake among those using non-prescribed gabapentin or using both prescribed and diverted gabapentin were to get high, increase the effects of heroin, substitute for opioids, and aid with opioid withdrawal. It has also been suggested that opioid-tolerant patients might desire the euphoric effects of new drugs such as the gabapentinoids.

Abuse of gabapentinoids typically involves supratherapeutic doses (i.e., pregabalin $>600 \mathrm{mg}$ and gabapentin $>3600 \mathrm{mg}$ ). Tachyphylaxis has been reported to develop rapidly and repeat abusers may therefore continue to increase the dose [73]. National drug utilization data have confirmed that many patients receive doses higher than recommended; this includes, for example, $8.5 \%$ and $9.6 \%$ of the patients prescribed pregabalin in Sweden [32] and Denmark [33], respectively. Analysis of pregabalin abuse/dependence adverse events in Germany revealed mean daily doses of $1424 \mathrm{mg}$ and a case series of recreational pregabalin abuse documented doses of 500-1400 mg [20]. In different case reports, doses varied from 800 to $7500 \mathrm{mg}$ and gabapentin doses between 1500 and 12,000 $\mathrm{mg}$ [69, 72, 74-77].

\subsection{Abuse Potential for Pregabalin and Gabapentin}

Available evidence suggests that pregabalin is the preferred gabapentinoid possibly owing to pharmacological differences between the two substances [1,3]. Pregabalin is absorbed more rapidly (maximum concentration within 1.5 hours) after oral intake and it has a higher bioavailability compared with gabapentin (>90\% vs 33-66\%) creating a faster onset of euphoria [1, 3, 78]. Moreover, gabapentin seems to have a dose-dependent absorption, giving a nonlinear dose-blood concentration relationship (at higher doses) $[1,3,78]$. Pregabalin is also stated to have a stronger inhibitory action on the $\alpha 2 \delta$-subunit-containing VGCC compared with gabapentin $[1,3]$.

There are a few studies where the abuse potential has been compared between the two substances. Overall, the abuse potential was shown to be higher for pregabalin than gabapentin based on adverse drug reporting data from the USA [17] and Europe [18]. Apart from pharmacovigilance and drug register studies and other systematic studies, there are several case presentations related to the abuse of gabapentinoids. These reports indicate that the dependence on pregabalin might be stronger and more sustaining than on gabapentin [78].

We have only found one study on the human abuse potential of the new gabapentinoid mirogabalin [79]. That study reported that supratherapeutic-dose mirogabalin was better liked by recreational polydrug users than users of placebo. However, there is no information available on the abuse potential of mirogabalin compared with pregabalin and/or gabapentin.

\subsection{Clinical Effects and Biological Mechanisms}

A meta-analysis of 38 clinical trials showed that euphoria was the second, most commonly reported adverse event 
for pregabalin [80], typically reported in individuals using higher pregabalin doses. Supratherapeutic doses may produce sedation, dissociation, relaxation, contentment, uninhibited behavior, improved sociability, empathy, and hallucinations $[68,72,77]$. Euphoria has also been reported to be significantly more common among pregabalin users than those treated with placebo [81]. Interestingly, early treatment response was improved in those who experienced euphoria. Somewhat different results were seen in a study by Zacny et al. [70] showing that abuse liability-related subjective effects such as drug liking and desire to take the drug again were not increased by pregabalin dose. Moreover, psychomotor performance was not affected by pregabalin use.

Several addictive drugs have in common that they increase the extracellular dopaminergic activity in the mesolimbic reward system [82-84]. This has however not been shown for gabapentinoids. A microdialysis study in rats found that gabapentin produced a modest increase in extracellular nucleus accumbens GABA levels but failed to alter either the basal or cocaine-enhanced dopamine activity in this key region of the reward system [5]. There have been speculations that there might be a different range of neurotransmitter involvement and receptor activation in high/very high pregabalin doses [85]. Pregabalin is a known inhibitor of the $\alpha 2 \delta$-subunit-containing VGCC. These VGCCs are located predominantly in presynaptic membranes and it has been demonstrated that gabapentinoids restrain stimulus-dependent synaptic transmitter release, mainly the excitatory transmitters glutamate and norepinephrine, but not dopamine [3, 4, 86]. Gabapentinoids might thereby act against aberrant neuronal over-excitation [87, 88]. Therapeutic doses of gabapentinoids are dose-dependently associated with a modest increase of the extracellular GABA concentration in brain tissue $[1,3,5,89]$, i.e., they have weak GABA mimetic features that might drive the relaxation and euphoria experienced in the beginning of drug therapy and during an overdose. For pregabalin, conditioned place preference test studies in rats indicated that only high intraperitoneal (but not oral) doses had an effect that could be interpreted as an ability to develop addiction [7]. It has been suggested that gabapentinoids may induce a subjective feeling of "liking" (euphoric high) owing to their GABA-mimetic action, but limited levels of behavioral dependence related to "wanting" [78].

A possible mechanism behind the fact that gabapentinoids often are combined with opioids has been suggested by Vashchinkina et al. [90]. Using a mice model, they found that pregabalin counteracted both the reinforcing and withdrawal effects of opioids. In addition, they also reported a potentiating effect of pregabalin on neuroplasticity leading to an increased conditioned place preference.

\subsection{Sources of the Drugs}

In a study from the UK [65], it was found that misused gabapentinoids most often are obtained from healthcare providers $(63 \%)$. Thus, many are prescribed the drugs but misuse it recreationally. The same pattern was seen in a US study [41]. Opioid-dependent patients admitted misuse in 50\% of cases of those prescribed pregabalin and in $40 \%$ of those prescribed gabapentin. Patients not prescribed a gabapentinoid admitted misuse of pregabalin in $6 \%$ of cases and gabapentin in $13 \%$ of cases. However, gabapentinoids are also readily available from drug dealers or the Internet [21, 49, 73]. To minimize cravings or continue to get 'highs' in the setting of mandatory urine controls or in a lack of other drugs of abuse [40, 42, 49, 72, 75], gabapentinoid abuse might be initiated to replace for example, cocaine or opioids $[75,91]$.

In general, there has been a notable increase in prescribing of gabapentinoids during the last 15 years. In a US adult population, the prevalence of gabapentin prescribing increased nearly two-fold from 2009 to 2016 [92]. Essentially, the same pattern was seen in a study of the use of gabapentinoid medications among US adults with cancer over the period 2005-15 [93] and in a UK study investigating prescribing trends of gabapentin and pregabalin over the years 2013-15 [94].

According to a recent US study using data from the National Ambulatory Medical Care Survey, a four-fold increase in annual gabapentinoid-involved visits was observed from 2003 to 2016 [95]. Concomitant use with other drugs such as opioids (32.9\%) or benzodiazepines $(15.3 \%)$ was frequent in these cases. Most of the gabapentinoids were prescribed by a primary care physician (45.8\%) and only few by a psychiatrist (4.8\%). However, it was noted that most $(96.6 \%)$ of the gabapentinoid visits did not have an approved indication for the gabapentinoids among the first three recorded diagnoses. The increase in gabapentinoid medication in the USA in recent years has been confirmed by other studies [92, 93]. The reason for the seemingly higher prevalence of prescription drug misuse/abuse of the gabapentinoids in the USA compared with European countries could at least partly be explained by differences in the prescriber's perception of the safety of gabapentinoids.

Prescribers in the USA, in contrast to European prescribers, might consider gabapentinoids a safer non-opioid pain medication in the context of the opioid overdose epidemic in the USA $[92,96]$. However, other differences in regulations, healthcare systems, ease of access, and perceptions by users might also add to these differences. However, the problem with the misuse of gabapentinoids was also reported 
as common in the UK, where a majority of gabapentinoid prescriptions were attributed to unlicensed indications and non-neuropathic painful conditions accounted for $80 \%$ of unlicensed gabapentin prescriptions and $50 \%$ of unlicensed pregabalin prescriptions [97], which has been confirmed in a recent UK study [94]. That is despite advice from Public Health England and the National Health Service England in 2014 [64].

\subsection{Risks with Abuse of Gabapentinoids}

At therapeutic doses, gabapentinoids seem to be well tolerated with the most common adverse effects from the central nervous system such as drowsiness, somnolence, dizziness, ataxia, and fatigue [89]. Withdrawal symptoms can be seen after immediate discontinuation of gabapentinoids suggesting physical dependence $[20,76,77,98,99]$. However, a recent study from Sweden [25] indicates that gabapentinoid users have an increased risk of suicidal behavior, unintentional overdoses, road traffic incidents, offences, and head/ body injuries. This was seen to a higher degree in gabapentin users compared to pregabalin users. Pregabalin has also been associated with withdrawal symptoms following rapid discontinuation, which might be related to suicidal behavior $[20,100,101]$. When participants with substance use disorders in the Swedish study [25] were excluded, there were no associations with unintentional overdoses and road traffic incidents and offences. This might indicate that simultaneous substance use increases the risk, which is in agreement with research showing that gabapentinoid misuse is higher among people who misuse opioids [64]. Moreover, overdoses of gabapentinoids are associated with respiratory depression and cardiac insufficiency if combined with sedatives and opioids $[48,78]$. Caution seems warranted when prescribing gabapentinoids to young people, especially those with substance use disorder as associations with adverse outcomes in general are mainly shown in younger age populations [25].

Several case reports and case series have been published describing non-fatal overdoses of gabapentinoids, most of them including other pharmaceuticals and often with blood supratherapeutic drug concentrations [47]. Similar findings have been found in DUID suspects [61]. Regarding fatalities after overdoses of gabapentinoids, there a number of retrospective studies from regional or national post-mortem toxicology registers in Finland [56-58] Sweden [30], Germany [102], and the UK [54]. The trend is that there is an increasing number of fatalities over the last 15-20 years in which gabapentinoids have been involved, mainly pregabalin. In almost all cases, other drugs have been found, mainly opioids, benzodiazepines, alcohol, and antidepressant drugs. In relation to sales, Ojanperä et al. [56] found that the Finnish number of deaths per million defined daily doses per year for pregabalin had an increasing trend from 2005 to 2013. Using this method for ranking the safety of 70 pharmaceuticals, pregabalin and gabapentin were ranked in the middle. An Irish study found an increase in the pregabalin poisoning deaths from 2013 to 2016 [51]. For gabapentin, it is still somewhat controversial whether a substantial overdose of gabapentin used alone is enough to induce life-threatening respiratory or cardiac insufficiency. There have been postmortem cases describing self-poisoning with gabapentin alone [103, 104]. Pregabalin overdosing may have fatal consequences, especially if combined with opioids and sedatives [54, 56, 62]. In summary, overdoses of gabapentinoids alone seem to be relatively well tolerated but can be lethal if combined with other drugs of abuse, such as opioids and sedatives.

\subsection{Recommendations to Healthcare Providers}

Like opioids or benzodiazepines, gabapentinoids are often used to treat conditions in which treatment efficacy is generally based on subjective measures (Fig. 1). Patients might, intentionally or unintentionally produce or overstate symptoms to obtain new prescriptions or higher doses $[68,105]$. It is important for prescribers to be aware of patients at risk of developing substance abuse. Patients with psychiatric disorders or substance use disorder (opioid abuse in particular)
Fig. 1 Recommendations to healthcare professionals and healthcare providers
- Health care professionals and health care providers must be aware of the misuse and abuse potential of pregabalin and gabapentin.

- Avoid if possible prescribing to patients belonging to risk populations such as psychiatric disorders or substance use disorder.

- Monitor signs of misuse and abuse in patients using these drugs.

- When new gabapentinoids are introduced on the market, the potential for misuse and abuse should be carefully investigated. 
seem to be at an increased risk. Therefore, prescribers and other healthcare professionals need to monitor signs of abuse or diversion in these patients [41]. Indicators of abuse might be requesting specific drugs, higher doses, or prescriptions from multiple sources, and claiming medications were lost. Given the frequent abuse and misuse of gabapentinoids, standard urine drug screening should include these substances [68]. In particular, patients undergoing opioid abuse treatment should be monitored in this manner. Moreover, it has been noted that individuals have admitted gabapentinoid abuse based on the knowledge that routine urine screening normally does not detect these substances $[49,72,106]$.

Other important measures to reduce the risk for potential abuse are limiting quantities prescribed, adequately managing pain disorders, prescribing off-label cautiously, and preventing withdrawal symptoms by tapering gabapentinoids if discontinued. Thus, clinicians should be cautious about prescribing gabapentinoids and must consider whether the benefits outweigh potential harms in the individual patient. Regarding off-label use, a recent review [96] concluded: "Finally, guidelines, review articles, and point-of-care resources should more explicitly note the limited evidence supporting gabapentinoid use for off-label indications and should resist promoting gabapentinoid use for any pain labelled as neuropathic." One issue not so often taken into consideration is the documentation of the treatment effect of gabapentinoids also in conditions where they are approved. One recent review of pregabalin in the management of neuropathic pain [107] concludes that pregabalin has a beneficial effect on some symptoms of neuropathic pain, but its use is associated with a number of adverse events and the overall quality of evidence supporting its use is low. The authors advocate a need for larger, robust, high-quality clinical trials with particular attention paid to minimizing selective reporting of outcomes. They also noted that the studies were usually short with a median duration of 9 weeks.

\subsection{Recommendations to Authorities}

Correlations between an increased prescription of gabapentinoids and an increased frequency of abuse/misuse [45], and between the numbers of dispensings of pregabalin and pregabalin-positive poisoning deaths [51] have been reported. In the USA, the increased pregabalin use has also been related to 'off-label' use as an alternative to opioids for various pain management [108]. Moreover, Rossow and Bramness [109] have shown that the consumption of prescription drugs with an abuse potential is skewedly distributed and that few excessive users account for a disproportionately high proportion of the drug sales.

To limit the non-medical off-label use of gabapentinoids, restrictions in prescription and use have been implemented. For example, pregabalin and gabapentin have been classified as a scheduled class C drug in the UK in 2019 [110], meaning that the prescriptions do not allow multiple dispensions and prescriptions are valid for just 1 month. The medical profession supported this change despite an extra burden for prescribers, pharmacists, and patients [111]. National e-prescription systems have also been proposed to prevent altered prescriptions or overlapping multiple prescriptions [112-114], especially prescription of central nervous system anti-depressant drugs from different prescribers [51].

Authorities should stimulate the reporting of suspected adverse drug events such as abuse and misuse of gabapentinoids and support researchers to analyze such data as well as other healthcare registers. A new interesting possibility is to analyze wastewater to study substance consumption, which provides a picture of changes, over time and between different areas, in the total consumption, including non-prescribed use [115].

\section{Conclusions}

The gabapentinoids, pregabalin and gabapentin are abused and misused particularly by those with a history of drug abuse. Those with an opioid use disorder seem to be more prone to abuse gabapentinoids than patients with other substance use disorders. Gabapentinoids are widely used in conditions where they are not approved and in higher doses than recommended. It seems that pregabalin is the preferred drug by abusers owing to pharmacological differences compared with gabapentin. Intoxications with gabapentinoids are characterized by an intake of other psychoactive substances as well and there seems to be an increasing number of fatalities over the last years. Most often, the gabapentinoids are obtained from healthcare providers. Physicians and healthcare providers have to find methods to avoid prescriptions of gabapentinoids to patients with a risk of abusing drugs. Clinical guidelines may have to be reviewed and further restrictions for off-label prescription might need to be considered.

Acknowledgments Open access funding provided by Linköping University.

\section{Declarations}

Funding No funding was received for the preparation of this article.

Conflicts of Interest/Competing Interests Staffan Hägg, Johan Ahlner, and Anna Jönsson have no conflicts of interest that are directly relevant to the content of this article.

Ethics Approval In Sweden, approval by an ethics committee is not needed for a review study using previously published data.

Consent to Participate Not applicable.

Consent for Publication Not applicable. 
Availability of Data and Material Data sharing is not applicable to this article as no datasets were generated or analyzed during the current study.

Code Availability Not applicable.

Author Contributions Conception and design: SH, JA, AJ. Acquisition, analysis, or interpretation of data: SH, JA, AJ. Drafting of the manuscript: SH, JA, AJ. Critical revision of the manuscript for important intellectual content: SH, JA, AJ.

Open Access This article is licensed under a Creative Commons Attribution-NonCommercial 4.0 International License, which permits any non-commercial use, sharing, adaptation, distribution and reproduction in any medium or format, as long as you give appropriate credit to the original author(s) and the source, provide a link to the Creative Commons licence, and indicate if changes were made. The images or other third party material in this article are included in the article's Creative Commons licence, unless indicated otherwise in a credit line to the material. If material is not included in the article's Creative Commons licence and your intended use is not permitted by statutory regulation or exceeds the permitted use, you will need to obtain permission directly from the copyright holder. To view a copy of this licence, visit http://creativecommons.org/licenses/by-nc/4.0/.

\section{References}

1. Calandre EP, Rico-Villademoros F, Slim M. Alpha 2 delta ligands, gabapentin, pregabalin and mirogabalin: a review of their clinical pharmacology and therapeutic use. Expert Rev Neurother. 2016;16:1263-77.

2. Deeks ED. Mirogabalin: first global approval. Drugs. 2019;79(4):463-8. https://doi.org/10.1007/s40265-019-01070-8.

3. Bockbrader HN, Wesche D, Miller R, Chapel S, Janiczek N, Burger P. A comparison of the pharmacokinetics and pharmacodynamics of pregabalin and gabapentin. Clin Pharmacokinet. 2010;49:661-9.

4. Rogawski MA, Bazil CW. New molecular targets for antiepileptic drugs: $\alpha_{2} \delta$, SV2A, and $\mathrm{K}_{\mathrm{v}} 7 / \mathrm{KCNQ} / \mathrm{M}$ potassium channels. Curr Neurol Neurosci Rep. 2008;8(4):345-52.

5. Peng XQ, Li X, Li J, Ramachandran PV, Gagare PD, Pratihar D, et al. Effects of gabapentin on cocaine self-administration, cocaine-triggered relapse and cocaine-enhanced nucleus accumbens dopamine in rats. Drug Alcohol Depend. 2008;97(3):207-15.

6. Andrews N, Loomis S, Blake R, Ferrigan L, Singh L, McKnight AT. Effect of gabapentin-like compounds on development and maintenance of morphine-induced conditioned place preference. Psychopharmacology. 2001;157(4):381-7.

7. Rutten K, De Vry J, Robens A, Tzschentke TM, Van Der Kam EL. Dissociation of rewarding, anti-aversive and anti-nociceptive effects of different classes of anti-nociceptives in the rat. Eur $\mathbf{J}$ Pain. 2011;15(3):299-305.

8. Coutens B, Mouledous L, Stella M, Rampon C, Lapeyre-Mestre $\mathrm{M}$, Roussin A, et al. Lack of correlation between the activity of the mesolimbic dopaminergic system and the rewarding properties of pregabalin in mouse. Psychopharmacology (Berl). 2019;236(7):2069-82. https://doi.org/10.1007/s00213-01905198-z.

9. Bura SA, Cabañero D, Maldonado R. Operant self-administration of pregabalin in a mouse model of neuropathic pain. Eur J Pain. 2018;22(4):763-73.
10. Pregabalin (pre-review report, agenda item 5.1). In: 39th Meeting of the Expert Committee on Drug Dependence; 6-10 November, 2017; Geneva.

11. Schjerning $O$, Rosenzweig M, Pottegård A, Damkier P, Nielsen J. Abuse potential of pregabalin: a systematic review. CNS Drugs. 2016;30(1):9-25.

12. European Medicines Agency. Guidelines on good pharmacovigilance practices (GPV). Module VI: management and reporting of adverse reactions to 5 medicinal products (Rev 1). London, UK: European Medicines Agency; 2013.

13. Blanch B, Buckley NA, Mellish L, Dawson AH, Haber PS, Pearson SA. Harmonizing post-market surveillance of prescription drug misuse: a systematic review of observational studies using routinely collected data (2000-2013). Drug Saf. 2015;38(6):553-64.

14. Directive 2010/84/EU of the European Parliament and the Council of 25 December, 2010 amending, as regards pharmacovigilance, Directive 2001/83/EC on the community code relating to medicinal products for human use; 2010.

15. American Academy of Pain Medicine, American Pain Society, and American Society of Addiction Medicine. Consensus document; 2001.

16. Vickers-Smith R, Sun J, Charnigo RJ, Lofwall MR, Walsh SL, Havens JR. Gabapentin drug misuse signals: a pharmacovigilance assessment using the FDA adverse event reporting system. Drug Alcohol Depend. 2020;206:107709. https://doi. org/10.1016/j.drugalcdep.2019.107709.

17. Evoy KE, Covvey JR, Peckham AM, Ochs L, Hultgren KE. Reports of gabapentin and pregabalin abuse, misuse, dependence, or overdose: an analysis of the Food And Drug Administration Adverse Events Reporting System (FAERS). Res Soc Adm Pharm. 2019;15(8):953-8. https://doi.org/10.1016/j.sapha rm.2018.06.018.

18. Chiappini S, Schifano F. A decade of gabapentinoid misuse: an analysis of the European Medicines Agency's 'suspected adverse drug reactions' database. CNS Drugs. 2016;30(7):647-54.

19. Bossard JB, Ponté C, Dupouy J, Lapeyre-Mestre M, Jouanjus E. Disproportionality analysis for the assessment of abuse and dependence potential of pregabalin in the French pharmacovigilance database. Clin Drug Investig. 2016;36(9):735-42. https:// doi.org/10.1007/s40261-016-0421-z.

20. Gahr M, Freudenmann RW, Hiemke C, Kölle MA, Schönfeldt-Lecuona C. Pregabalin abuse and dependence in Germany: results from a database query. Eur J Clin Pharmacol. 2013;69(6):1335-42.

21. Schwan S, Sundström A, Stjernberg E, Hallberg E, Hallberg P. A signal for an abuse liability for pregabalin-results from the Swedish spontaneous adverse drug reaction reporting system. Eur J Clin Pharmacol. 2010;66(9):947-53.

22. Crossin R, Scott D, Arunogiri S, Smith K, Dietze PM, Lubman DI. Pregabalin misuse-related ambulance attendances in Victoria, 2012-2017: characteristics of patients and attendances. Med J Aust. 2019;210(2):75-9.

23. Piper BJ, Suarez MJ, Piserchio JP, Shah DT, Simoyan OM, McCall KL, et al. Illicit and prescription drug misuse as reported to the Maine Diversion Alert Program. Forensic Sci Int. 2018;285:65-71. https://doi.org/10.1016/j.forsciint.2018.01.025.

24. Buttram ME, Kurtz SP, Dart RC, Margolin ZR. Law enforcement-derived data on gabapentin diversion and misuse, 20022015: diversion rates and qualitative research findings. Pharmacoepidemiol Drug Saf. 2017;26(9):1083-6.

25. Molero Y, Larsson H, D'Onofrio BM, Sharp DJ, Fazel S. Associations between gabapentinoids and suicidal behaviour, unintentional overdoses, injuries, road traffic incidents, and violent crime: Population based cohort study in Sweden. BMJ. 2019;2019:365. https://doi.org/10.1136/bmj.12147. 
26. Driot D, Jouanjus E, Oustric S, Dupouy J, Lapeyre-Mestre M. Patterns of gabapentin and pregabalin use and misuse: results of a population-based cohort study in France. Br J Clin Pharmacol. 2019;85(6):1260-9.

27. Cairns R, Schaffer AL, Ryan N, Pearson SA, Buckley NA. Rising pregabalin use and misuse in Australia: trends in utilization and intentional poisonings. Addiction. 2019;114(6):1026-34.

28. Peckham AM, Fairman KA, Sclar DA. Prevalence of gabapentin abuse: comparison with agents with known abuse potential in a commercially insured US population. Clin Drug Investig. 2017;37(8):763-73. https://doi.org/10.1007/s40261-017-0530.

29. Lyndon A, Audrey S, Wells C, Burnell ES, Ingle S, Hill R, et al. Risk to heroin users of polydrug use of pregabalin or gabapentin. Addiction. 2017;112(9):1580-9.

30. Abrahamsson T, Berge J, Öjehagen A, Håkansson A. Benzodiazepine, z-drug and pregabalin prescriptions and mortality among patients in opioid maintenance treatment: a nation-wide registerbased open cohort study. Drug Alcohol Depend. 2017;174:5864. https://doi.org/10.1016/j.drugalcdep.2017.01.013.

31. Asomaning K, Abramsky S, Liu Q, Zhou X, Sobel RE, Watt S. Pregabalin prescriptions in the United Kingdom: a drug utilisation study of the Health Improvement Network (THIN) primary care database. Int J Clin Pract. 2016;70(5):380-8.

32. Schjerning $O$, Pottegård A, Damkier P, Rosenzweig M, Nielsen J. Use of pregabalin: nationwide pharmacoepidemiological drug utilization study with focus on abuse potential. Pharmacopsychiatry. 2016;49(4):155-61. https://doi.org/10.1055/s-0042-10186 8.

33. Bodén R, Wettermark B, Brandt L, Kieler H. Factors associated with pregabalin dispensing at higher than the approved maximum dose. Eur J Clin Pharmacol. 2014;70(2):197-204.

34. Stein MD, Kenney SR, Anderson BJ, Conti MT, Bailey GL. Prescribed and non-prescribed gabapentin use among persons seeking inpatient opioid detoxification. J Subst Abuse Treat. 2020;110:37-41. https://doi.org/10.1016/j.jsat.2019.12.007.

35. Al-Husseini A, Abu-Farha R, Wazaify M, Van Hout MC. Pregabalin dispensing patterns in Amman-Jordan: an observational study from community pharmacies. Saudi Pharm J. 2018;26(3):306-10. https://doi.org/10.1016/j.jsps.2018.01.012.

36. Al-Husseini A, Wazaify M, Van Hout MC. Pregabalin misuse and abuse in Jordan: a qualitative study of user experiences. Int $\mathbf{J}$ Ment Health Addict. 2018;16(3):642-54. https://doi.org/10.1007/ s11469-017-9813-4.

37. Vickers-Smith R, Boland EM, Young AM, Lofwall MR, Quiroz A, Staton M, et al. A qualitative analysis of gabapentin misuse and diversion among people who use drugs in Appalachian Kentucky. Psychol Addict Behav. 2018;32(1):115-21.

38. Snellgrove BJ, Steinert T, Jaeger S. Pregabalin use among users of illicit drugs: a cross-sectional survey in Southern Germany. CNS Drugs. 2017;31(10):891-8.

39. Bastiaens L, Galus J, Mazur C. Abuse of gabapentin is associated with opioid addiction. Psychiatr Q. 2016;87(4):763-7.

40. Alblooshi H, Hulse GK, El Kashef A, Al Hashmi H, Shawky $\mathrm{M}, \mathrm{Al}$ Ghaferi $\mathrm{H}$, et al. The pattern of substance use disorder in the United Arab Emirates in 2015: results of a National Rehabilitation Centre cohort study. Subst Abus Treat Prev Policy. 2016;11(19):1-11. https://doi.org/10.1186/s13011-016-0062-5.

41. Wilens T, Zulauf C, Ryland D, Carrellas N, Catalina-Wellington I. Prescription medication misuse among opioid dependent patients seeking inpatient detoxification. Am J Addict. 2015;24(2):173-7.

42. Baird CRW, Fox P, Colvin LA. Gabapentinoid abuse in order to potentiate the effect of methadone: A survey among substance misusers. Eur Addict Res. 2014;20(3):115-8.

43. Elsayed M, Zeiss R, Gahr M, Connemann BJ, Schönfeldt-Lecuona $\mathrm{C}$. Intranasal pregabalin administration: a review of the literature and the worldwide spontaneous reporting system of adverse drug reactions. Brain Sci. 2019;9(11):322.

44. Wills B, Reynolds P, Chu E, Murphy C, Cumpston K, Stromberg $\mathrm{P}$, et al. Clinical outcomes in newer anticonvulsant overdose: a poison center observational study. J Med Toxicol. 2014;10(3):254-60.

45. Daly C, Griffin E, Ashcroft DM, Webb RT, Perry IJ, Arensman E. Intentional drug overdose involving pregabalin and gabapentin: findings from the National Self-Harm Registry Ireland, 2007-2015. Clin Drug Investig. 2018;38(4):373-80. https://doi. org/10.1007/s40261-017-0616-y.

46. Gomes T, Juurlink DN, Antoniou T, Mamdani MM, Paterson JM, van den Brink W. Gabapentin, opioids, and the risk of opioid-related death: a population-based nested case-control study. PLoS Med. 2017;14(10):e1002396. https://doi.org/10.1371/journ al.pmed.1002396.

47. Klein-Schwartz W, Shepherd JG, Gorman S, Dahl B. Characterization of gabapentin overdose using a poison center case series. J Toxicol Clin Toxicol. 2003;41(1):11-5.

48. McNamara S, Stokes S, Kilduff R, Shine A. Pregabalin abuse amongst opioid substitution treatment patients. Ir Med J. 2015;108(10):1-2.

49. Grosshans M, Lemenager T, Vollmert C, Kaemmerer N, Schreiner R, Mutschler J, et al. Pregabalin abuse among opiate addicted patients. Eur J Clin Pharmacol. 2013;69(12):2021-5.

50. Reynolds K, Kaufman R, Korenoski A, Fennimore L, Shulman J, Lynch M. Trends in gabapentin and baclofen exposures reported to US poison centers. Clin Toxicol. 2020;58(7):763-72. https:// doi.org/10.1080/15563650.2019.1687902.

51. Lynn E, Cousins G, Lyons S, Bennett KE. A repeated crosssectional study of factors associated with pregabalin- positive poisoning deaths in Ireland. Drug Alcohol Depend. 2020;206:107741. doi: 10.1016/j.drugalcdep.2019.107741 and Lynn E, Cousins G, Lyons S, Bennett KE. Corrigendum to "A repeated cross-sectional study of factors associated with pregabalin-positive poisoning deaths in Ireland". Drug Alcohol Depend. 2020;210:107956.

52. Thompson A, Morey S, Griffiths A. Pregabalin and its involvement in coronial cases. J Anal Toxicol. 2020;44(1):29-35. https ://doi.org/10.1093/jat/bkz041.

53. Slavova S, Miller A, Bunn TL, White JR, Kirschke D, Light T, et al. Prevalence of gabapentin in drug overdose postmortem toxicology testing results. Drug Alcohol Depend. 2018;186:80-5. https://doi.org/10.1016/j.drugalcdep.2018.01.018.

54. Eastwood JA, Davison E. Pregabalin concentrations in post-mortem blood: a two year study. Forensic Sci Int. 2016;266:197-201. https://doi.org/10.1016/j.forsciint.2016.05.033.

55. Haukka J, Kriikku P, Mariottini C, Partonen T, Ojanperä I. Nonmedical use of psychoactive prescription drugs is associated with fatal poisoning. Addiction. 2018;113(3):464-72.

56. Ojanperä I, Kriikku P, Vuori E. Fatal toxicity index of medicinal drugs based on a comprehensive toxicology database. Int $\mathbf{J}$ Legal Med. 2016;130(5):1209-16. https://doi.org/10.1007/s0041 4-016-1358-8.

57. Häkkinen M, Vuori E, Kalso E, Gergov M, Ojanperä I. Profiles of pregabalin and gabapentin abuse by postmortem toxicology. Forensic Sci Int. 2014;241:1-6.

58. Launiainen T, Broms U, Keskitalo-Vuokko K, Pitkäniemi J, Pelander A, Kaprio J, et al. Nicotine, alcohol, and drug findings in young adults in a population-based postmortem database. Nicotine Tob Res. 2011;13(9):763-71.

59. Tharp AM, Hobron K, Wright T. Gabapentin-related deaths: patterns of abuse and postmortem levels. J Forensic Sci. 2019;64(4):1105-11. https://doi.org/10.1111/1556-4029.14021. 
60. Peterson BL. Prevalence of gabapentin in impaired driving cases in Washington State in 2003-2007. J Anal Toxicol. 2009;33(8):545-9.

61. Kriikku P, Wilhelm L, Rintatalo J, Hurme J, Kramer J, Ojanperä I. Pregabalin serum levels in apprehended drivers. Forensic Sci Int. 2014;243:112-6.

62. Elliott SP, Burke T, Smith C. Determining the toxicological significance of pregabalin in fatalities. J Forensic Sci. 2017;62(1):169-73.

63. Hamm CE, Gary RD, McIntyre IM. Gabapentin concentrations and postmortem distribution. Forensic Sci Int. 2016;262:201-3. https://doi.org/10.1016/j.forsciint.2016.03.028.

64. Smith RV, Havens JR, Walsh SL. Gabapentin misuse, abuse and diversion: a systematic review. Addiction. 2016;111:1160-74.

65. Kapil V, Green JL, Le Lait MC, Wood DM, Dargan PI. Misuse of the $\gamma$-aminobutyric acid analogues baclofen, gabapentin and pregabalin in the UK. Br J Clin Pharmacol. 2014;78(1):190-1.

66. Lancia M, Gambelunghe A, Gili A, Bacci M, Aroni K, Gambelunghe $\mathrm{C}$. Pregabalin abuse in combination with other drugs: monitoring among methadone patients. Front Psychiatry. 2020;10:1-8.

67. Smith RV, Lofwall MR, Havens JR. Abuse and diversion of gabapentin among nonmedical prescription opioid users in Appalachian Kentucky. Am J Psychiatry. 2015;172(5):487-8.

68. Smith BH, Higgins C, Baldacchino A, Kidd B, Bannister J. Substance misuse of gabapentin. Br J Gen Pract. 2012;62(601):406-7.

69. Reccoppa L, Malcolm R, Ware M. Gabapentin abuse in inmates with prior history of cocaine dependence. Am J Addict. 2004;13(3):321-3.

70. Zacny JP, Paice JA, Coalson DW. Subjective, psychomotor, and physiological effects of pregabalin alone and in combination with oxycodone in healthy volunteers. Pharmacol Biochem Behav. 2012;100(3):560-5. https://doi.org/10.1016/j.pbb.2011.10.023.

71. Chatterjee A, Lopez D, Ramkellawan S, Brown R, Smith K, Gaeta JM, et al. "That's what we call the cocktail": non-opioid medication and supplement misuse among opioid users. Subst Abus. 2019;22:1-8. https://doi.org/10.1080/08897 077.2019.1671943.

72. Reeves RR, Ladner ME. Potentiation of the effect of buprenorphine/naloxone with gabapentin or quetiapine. Am J Psychiatry. 2014;171(6):691.

73. Schifano F, D’Offizi S, Piccione M, Corazza O, Deluca P, Davey $\mathrm{Z}$, et al. Is there a recreational misuse potential for pregabalin? Analysis of anecdotal online reports in comparison with related gabapentin and clonazepam data. Psychother Psychosom. 2011;80(2):118-22.

74. Kruszewski SP, Paczynski RP, Kahn DA. Gabapentin-induced delirium and dependence. J Psychiatr Pract. 2009;15(4):314-9.

75. Satish R, Kandasamy A, Jayarajan D, Benegal V. Gabapentin dependence in a patient with opioid dependence syndrome. J Neuropsychiatry Clin Neurosci. 2015;27(1):e64. https://doi. org/10.1176/appi.neuropsych.13110339.

76. Filipetto FA, Zipp CP, Coren JS. Potential for pregabalin abuse or diversion after past drug-seeking behavior. J Am Osteopath Assoc. 2010;110(10):605-7.

77. Grosshans M, Mutschler J, Hermann D, Klein O, Dressing H, Kiefer F, et al. Pregabalin abuse, dependence, and withdrawal: a case report. Am J Psychiatry. 2010;167(7):869. https://doi. org/10.1176/appi.ajp.2010.09091269.

78. Bonnet U, Scherbaum N. How addictive are gabapentin and pregabalin?. Eur Neuropsychopharmacol. 2017;27(12):1185-215. https://doi.org/10.1016/j.euroneuro.2017.08.430.

79. Mendell J, Levy-Cooperman N, Sellers E, Vince B, Kelsh D, Lee $\mathrm{J}$, et al. Abuse potential of mirogabalin in recreational polydrug users. Ther Adv Drug Saf. 2019;10:2042098619836032.
80. Zaccara G, Gangemi P, Perucca P, Specchio L. The adverse event profile of pregabalin: a systematic review and meta-analysis of randomized controlled trials. Epilepsia. 2011;52(4):826-36.

81. Parsons B, Freynhagen R, Schug S, Whalen E, Ortiz M, Brown $\mathrm{PB}$, et al. The relationship between the reporting of euphoria events and early treatment responses to pregabalin: an exploratory post-hoc analysis. J Pain Res. 2019;12:2577-87.

82. Pontieri FE, Tanda G, Di Chiara G. Intravenous cocaine, morphine, and amphetamine preferentially increase extracellular dopamine in the "shell" as compared with the "core" of the rat nucleus accumbens. Proc Natl Acad Sci USA. 1995;92(26):12304-8

83. Karoly HC, Yorkwilliams SL, Hutchison KE. Clinical neuroscience of addiction: similarities and differences between alcohol and other drugs. Alcohol Clin Exp Res. 2015;39(11):2073-84.

84. Volkow ND, Morales M. The brain on drugs: from reward to addiction. Cell. 2015;162(4):712-25. https://doi.org/10.1016/j. cell.2015.07.046.

85. Schifano F, Chiappini S. Pregabalin: a range of misuse-related unanswered questions. CNS Neurosci Ther. 2019;25(5):659-60.

86. Dooley DJ, Donovan CM, Pugsley TA. Stimulus-dependent modulation of $[3 \mathrm{H}]$ norepinephrine release from rat neocortical slices by gabapentin and pregabalin. J Pharmacol Exp Ther. 2000;295(3):1086-93.

87. Eroglu Ç, Allen NJ, Susman MW, O'Rourke NA, Park CY, Özkan E, et al. Gabapentin receptor alpha2delta-1 is a neuronal thrombospondin receptor responsible for excitatory CNS synaptogenesis. Cell. 2009;139(2):380-92.

88. Micó JA, Prieto R. Elucidating the mechanism of action of pregabalin: $\alpha(2) \delta$ as a therapeutic target in anxiety. CNS Drugs. 2012;26(8):637-48.

89. Cai K, Nanga RPR, Lamprou L, Schinstine C, Elliott M, Hariharan $\mathrm{H}$, et al. The impact of gabapentin administration on brain GABA and glutamate concentrations: A $7 \mathrm{~T}^{1} \mathrm{H}-\mathrm{MRS}$ study. Neuropsychopharmacology. 2012;37(13):2764-71.

90. Vashchinkina E, Piippo O, Vekovischeva O, Krupitsky E, Ilyuk $\mathrm{R}$, Neznanov N, et al. Addiction-related interactions of pregabalin with morphine in mice and humans: reinforcing and inhibiting effects. Addict Biol. 2018;23(3):945-58.

91. Markowitz JS, Finkenbine R, Myrick H, King L, Carson WH. Gabapentin abuse in a cocaine user: implications for treatment? J Clin Psychopharmacol. 1997;17(5):423-4.

92. Pauly NJ, Delcher C, Slavova S, Lindahl E, Talbert J, Freeman $\mathrm{PR}$. Trends in gabapentin prescribing in a commercially insured US adult population, 2009-2016. J Manag Care Spec Pharm. 2020;26(3):246-52.

93. Fauer AJ, Davis MA, Choi SW, Wallner LP, Friese CR. Use of gabapentinoid medications among US adults with cancer, 2005-2015. Support Care Cancer. 2020;28(1):5-8.

94. Green K, Cooke O'Dowd N, Watt H, Majeed A, Pinder RJ. Prescribing trends of gabapentin, pregabalin, and oxycodone: a secondary analysis of primary care prescribing patterns in England. BJGP Open. 2019;3(3):bjgpopen19X101662.

95. Zhou L, Bhattacharjee S, Kwoh CK, Tighe PJ, Malone DC, Slack $\mathrm{M}$, et al. Trends, patient and prescriber characteristics in gabapentinoid use in a sample of United States ambulatory care visits from 2003 to 2016. J Clin Med. 2020;9(1):1-8.

96. Goodman CW, Brett AS. A clinical overview of off-label use of gabapentinoid drugs. JAMA Intern Med. 2019;179(5):695-701.

97. Montastruc F, Loo SY, Renoux C. Trends in first gabapentin and pregabalin prescriptions in primary care in the United Kingdom, 1993-2017. JAMA. 2018;320:2149-51. https://doi.org/10.1001/ jama.2018.12358.

98. Mah L, Hart M. Gabapentin withdrawal: case report in an older adult and review of the literature. J Am Geriatr Soc. 2013;61(9):1635-7. 
99. Hellwig TR, Hammerquist R, Termaat J. Withdrawal symptoms after gabapentin discontinuation. Am J Health Syst Pharm. 2010;67(11):910-2.

100. Toth C. Pregabalin: Latest safety evidence and clinical implications for the management of neuropathic pain. Ther Adv Drug Saf. 2014;5(1):38-56.

101. Baldwin DS, Ajel K, Masdrakis VG, Nowak M, Rafiq R. Pregabalin for the treatment of generalized anxiety disorder: an update. Neuropsychiatr Dis Treat. 2013;9:883-92.

102. Lottner-Nau S, Ovguer B, Paul LD, Graw M, Sachs H, Roider G. Abuse of pregabalin: results of the postmortem toxicology from 2010-2012. Toxichem Krimtech. 2013;80:339-42.

103. Middleton O. Suicide by gabapentin overdose. J Forensic Sci. 2011;56(5):1373-5.

104. Cantrell FL, Mena O, Gary RD, McIntyre IM. An acute gabapentin fatality: a case report with postmortem concentrations. Int J Legal Med. 2015;129(4):771-5.

105. Spence D. Bad medicine: gabapentin and pregabalin. BMJ. 2013;347:2012-3. https://doi.org/10.1136/bmj.f6747.

106. Reeves RR, Burke RS. Abuse of combinations of gabapentin and quetiapine. Prim Care Companion CNS Disord. 2014;16:5. https ://doi.org/10.4088/pcc. 14101660.

107. Onakpoya IJ, Thomas ET, Lee JJ, Goldacre B, Heneghan CJ. Benefits and harms of pregabalin in the management of neuropathic pain: a rapid review and meta-analysis of randomised clinical trials. BMJ Open. 2019;9(1):e023600.

108. Goodman CW, Brett AS. Gabapentin and pregabalin for pain: is increased prescribing a cause for concern? $\mathrm{N}$ Engl $\mathrm{J}$ Med. 2017;377(5):411-4.

109. Rossow I, Bramness JG. The total sale of prescription drugs with an abuse potential predicts the number of excessive users: a national prescription database study. BMC Public Health. 2015;15(1):1-9.

110. Home Office. Atkins V. Pregabalin and gabapentin to be controlled as class C drugs. 2018. www.gov.uk/government/news/ pregabalin-and-gabapentin-to-be-controlled-as-class-c-drugs . Accessed 4 Aug 2020.

111. Torjesen I. Pregabalin and gabapentin: what impact will reclassification have on doctors and patients? BMJ. 2019;364:11107. https://doi.org/10.1136/bmj.11107.

112. Clark M, Hamdi-Ghoz E, Jauffret-Roustide M, Le Moigne P, Melpomeni Malliori M, Simeoni E, et al. The gender dimension of non-medical use of prescription drugs in Europe and the Mediterranean Region. 2015. https://rm.coe.int/16805938a9 . Accessed 4 Aug 2020.

113. Health Information and Quality Authority, 2015. ePrescription dataset and clinical document architecture standard. 2015. http:// web.archive.org/save/https://www.hiqa.ie/reports-and-publicatio $\mathrm{ns} /$ health-information/ eprescription-dataset-and-clinical-document. Accessed 4 Aug 2020.

114. Health Service Executive, 2019. Primary care reimbursement service annual reports: statistical analysis of claims and payments. 2019. http://web.archive.org/save/https://www.sspcrs.ie/ portal/annual-reporting/report/annual. Accessed 4 Aug 2020.

115. Choi PM, Tscharke B, Samanipour S, Hall WD, Gartner CE, Mueller JF, et al. Social, demographic, and economic correlates of food and chemical consumption measured by wastewater-based epidemiology. Proc Natl Acad Sci USA. 2019;116(43):21864-73. 